IndonesiaDLN - papers/asist-paper-contest-ismail.htm

Use font style

\title{
THE INDONESIAN DIGITAL LIBRARY NETWORK \\ IS BORN TO STRUGGLE WITH \\ THE DIGITAL DIVIDE
}

Ismail Fahmi ${ }^{[2]}$

\begin{abstract}
IndonesiaDLN - The Indonesian Digital Library Network - is a distributed collection of digital library networks, digital library servers, full local contents, metadata, and people for the development of the Indonesian knowledgebased society. Beside the general issues of digital library such as publishing, quality control, authentication, networking, and information retrieval, we also face other issue -namely digital divide- in designing and implementing the Network. This paper describes basic design of the Network that able to handle the typical problems in developing digital library network in Indonesia as a developing country, such as internet accessibility, bandwidth capacity, and network delays. We also will describe our experiences in implementing the Network that currently has 14 successfully connected partners and more than 15 partners are in progress of developing their digital library servers.
\end{abstract}

\section{Introduction: The Indonesian Digital Library Network}

The Indonesian Digital Library Network, IndonesiaDLN, is the first digital library network in Indonesia, http://idln.itb.ac.id. The development was pioneered and motored by Knowledge Management Research Group (KMRG) at Institut Teknologi Bandung (ITB) Indonesia, together with other librarians and information engineers. This work was carried out with the aid of a grant from the International Development Research Centre (IDRC) Canada and the Indonesian Foundation for Telecommunication and Information Research (YLTI) for the period of 2000-2002. Other organization that support this work are Asian Internet Interconnection Initiative (AI3) ITB, ITB Central Library, and Computer Network Research Group (CNRG) ITB [1].

We also have a good collaboration with EIUDP, The Eastern Indonesian University Development Project that is supported by Simon Fraser University and CIDA. Also has collaboration with McGill University and Indonesian Ministry of Religion Affair in developing digital library network for IAIN, The Indonesian Islamic Institutes.

KMRG ITB has started research on the digital library network since 1998. Then establishment of the IndonesiaDLN forum was initiated at October 2000. The first operation of the network was launched at June 2001.

The mission of IndonesiaDLN is to unlock knowledge of Indonesian people - especially the local content -- and share it nationally. It means to provide information about Indonesia such as about their final project, theses, dissertation, research report, heritage, regional potency, history, etc in an easy way, user friendly, distributed, and invite contribution from Indonesian people widely. Such information will be very useful to increase nation's information literate, collaboration among them, and to promote Indonesia to international.

IndonesiaDLN has a wide range of partners such as from research, education, business, NGO, government, etc. This will create a big national knowledgebase that should be maintained and organized again becoming more useful information package series. For example we could make series of children education, theses and dissertation, national heritage, human right and democratic, etc.

IndonesiaDLN is to be said as a mother network of digital library network in Indonesia. It is because there will be many networks connected to IndonesiaDLN.

There is as a hub that will unify all metadata from all digital library networks in Indonesia. Currently there are two 
networks of digital library joined within IndonesiaDLN, namely GDL-Network and NS-Network.

\subsection{GDL-Network}

GDL-Network is network of digital library servers that use Ganesha Digital Library (GDL) software as their server application. GDL is developed by KMRG ITB as one of its research outputs by a grant from IDRC and YLTI. It is developed using PHP scripting language, MySQL database server, and Apache web server. GDL is distributed as a free-software and the source code can be downloaded at http://gdl.itb.ac.id/download/.

Currently, GDL is the most widely used application by IndonesiaDLN partners. The same source code can be installed for three types of partners: Institution, Personal, and Internet Cafe. Contribution from the partners can be viewed at http://gdlhub.indonesiaDLN.org.

Figure 1 bellow shows GDL-Hub front page that contains list and link to the publishers -partners of GDL-Network - and number of electronic collections they have been published and shared to IndonesiaDLN. Some of the publishers use dial-up connection to synchronize their collections to GDL-Hub (marked with publisher name WITHOUT link), while others use dedicated connection (marked with publisher name WITH link to its original site).

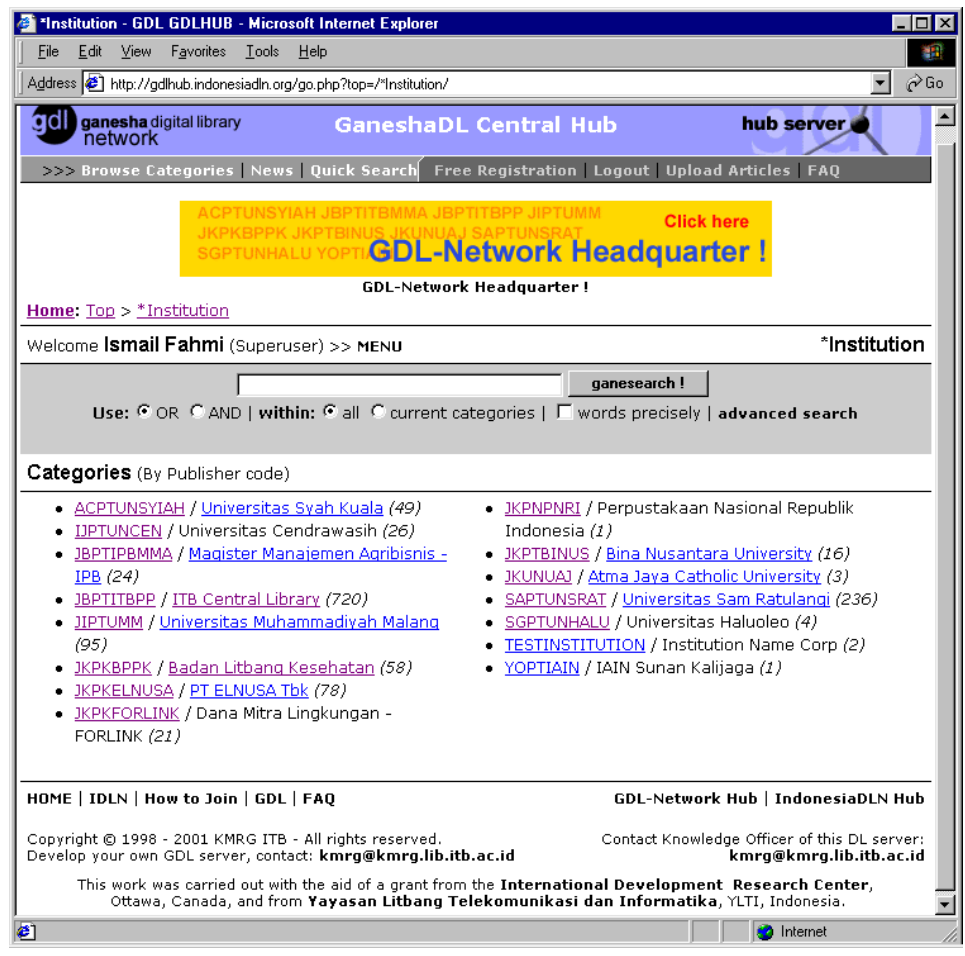

Figure 1. The gateway to IndonesiaDLN's partners collection, http://gdlhub.indonesiaDLN.org.

\subsection{NS-Network}

NS-Network is network of digital library servers that use New Spektra (NS) as the server application. NS is developed by University of Petra Surabaya Indonesia especially for members of their Christian university consortium.

\subsection{Other Efforts}

There are several other digital library efforts in Indonesia such as by KMNRT, LIPI, etc. In the future IndonesiaDLN also will support information about heritage, human right, and agricultural.

By using the standardized interoperability metadata, we hope can integrate the digital libraries into one national digital library network.

\section{The Potential Assets of Information}


Indonesia has 210 million inhabitants that are living at thousands of islands. There are thousands of tribes, hundreds of languages, and invaluable cultural assets. Indonesian past history was colored by the life of kingdoms. We can find many inheritances that are archived at National Library, National Archive, Museums, etc. But ironically if want to learn more about Java history for example, we have to go to Leiden at Netherlands. There, such things are archived, maintained, and organized very well. Dutch brought the collections in the colonialism period.

Indonesia is now entering a new era of autonomy. The central government gives autonomy to the territories to manage their own zone. The territorial governments have to manage information about their territories assets in order to get advantages from national and international affairs. For example heritage asset is one of the most important assets that will invite economics and cultural activities such as trading, tourism, education, exploration, etc. In this field, Indonesia is well known by its cultural diversity.

Other interesting asset is its natural asset. Assorted by thousands separated tropical islands; Indonesia is very rich with its natural variety. These attract researchers and business to do exploration. For example, there are many plantation species that can be used for traditional medicines, etc.

Now days, it is difficult to find information about above assets. There are several causes such as lack of documentation and information center, lack and expensiveness of information and telecommunication facilities, quality of researches result and their publications, lack of the qualified and complete online information center, etc. LIPI, The Indonesian Science Institute, has tried to publish its research result and information regarding to Indonesia whether online or using hardcopy. But for this moment it can't fulfill the information demand to support the development of Indonesia.

All of these conditions become challenges for every university, research institution, territorial government, and every institution to manage their local information and knowledge. The growing of internet has brought them to the need of providing online information. By managing and publishing local knowledge, in the near future we hope can accumulate the national knowledge.

\section{IndonesiaDLN and The Digital Divide Challenges}

There is no other effective and efficient way to integrate information from the separated islands of Indonesia compared with the use of information and telecommunication technology (ICT). What we need is a distributed information center and internetworking among the centers so that we can manage and use information from many center sources easily and fast.

We develop a digital library system that will act as the information center. This system can be implemented easily at any places, because it doesn't need a big room or complicated preparation as needed by a common information center. At the minimal technical configuration, we only need a personal computer with a dial-up modem. Among the digital library systems we develop an internetworking and then become a network called the Indonesian Digital Library Network or IndonesiaDLN.

\subsection{Struggling with the Digital Divide}

IndonesiaDLN was designed especially for Indonesia or other typical developing countries, where the digital gap is most evident at the phase of connectivity: the lack of affordable access to PCs, Internet devices, modems, telephone lines, and Internet connections. There is a gap of ICT application where some regions have enough access to ICT but some others (the most) are difficult to get the access.

This called digital divide not only happens between regions in a country, but also between nations. To struggle with the digital divide, we must address access, content, and commerce issues. There are eight spectrums of parameters where the gaps tend to emerge along, namely connectivity, content, community, commerce, capacity, culture, cooperation, and capital. These are the eight Cs of success in the Internet economy [2].

We can summed up the recommendations to narrow the gaps as follow:

- Connectivity; The digital gap is most evident at the phase of connectivity: the lack of affordable access to PCs, Internet devices, modems, telephone lines, and Internet connections. Steps to reduce this gap include devising cheaper access devices (such as publicly accessible kiosks), lowering tariffs on the import of computers and modems, creating Internet community access centers (with leased lines and shared devices), 
and bringing down access prices by creating a favorable climate of competition among Internet service providers (ISPs).

- Content; Emerging economies need to increase activity in order to help reduce the content gap. News media, public health services, government-citizen resources, NGOs, SMEs, and emergency relief organizations need to make more content and services available online. World-class hosting infrastructure must be created in emerging economies so that locally generated content will be hosted predominantly in the region and not outside it, thereby saving lucrative foreign exchange revenues and safeguarding information sovereignty.

- Community; While much attention is focused on Web publishing, e-mail forums for content distribution and discussion still can play a useful role-especially in areas where bandwidth is low and the quality of phone connections is poor. E-mail-based discussion lists are an underutilized channel in online communications for many of the emerging economies.

- Commerce; To move beyond being mere destinations for e-commerce sales from U.S. and European sites, emerging economies need to close the e-commerce gap by effectively building a domestic Internet economy and promoting online transactional capabilities for the consumer, business, and government sectors-B2C, $\mathrm{B} 2 \mathrm{~B}, \mathrm{C} 2 \mathrm{C}, \mathrm{G} 2 \mathrm{C}$, and $\mathrm{G} 2 \mathrm{~B}$. This includes the updating of existing business and intellectual property rights laws to accommodate electronic contracts, online funds transfer, and stronger consumer fraud protection laws.

- Capacity; To close the digital skills gap, emerging economies need to improve the capacity of their workforces to play roles in the Internet age. This includes improving Internet access and educational offerings in schools and colleges, creating digital libraries for universities, and promoting professional training institutes.

- Culture; Culture represents probably the biggest challenge in closing the digital gap. It involves overcoming cultural inhibitions and insecurities about developing competence for surviving the breakneck speed of the Internet age. Closing the culture gap includes getting governments in emerging economies to stop treating their telecom monopolies like cash cows and instead, getting government telecom players to invest in areas like $R \& D$ on Internet telephony, so that the technology is seen as a market opportunity on a global scale and not a threat on a local scale. It also includes getting career-track diplomats, bureaucrats, academics, and public-sector employees to take up Internet training and harness the opportunities as well as the plentiful challenges that accompany Internet diffusion.

- Cooperation; No single sector can take on the Internet economy by itself; much cooperation at the national level is needed to overcome the gaps between government, academia, the private sector, civil society, and international organizations. This should happen at the state or provincial, national, and regional levels; it can also extend to groupings based on culture or language.

- Capital; The highly volatile Internet economy is making it all too evident that an Internet initiative can best survive if it is economically self-sustaining. Therefore, government should focus on creating open investment climates for the incubation, launch, acceleration, and initial-public-offering phases of an Internet start-up. The government need not spend excessive funds on incubation projects of its own; it should create conditions and safeguards conducive to the movement of domestic and international capital into the New Economy.

\subsection{Internet Connectivity in Indonesia}

The digital gaps between Indonesia and other countries can be easily seen from the connectivity parameter. According to the Indonesian Internet Statistics [3] there are more than 150 licenses issued by the Government (Dirjen Postel: Post and Telecommunication). From these 150 lincenses, only about 40 ISPs are operating. Many of them aquire lincenses just to go into VoIP (Voice over IP) business.

Most ISPs are located in Jakarta area. In other parts of Indonesia, only Wasantara net (wasantara.net.id) is available. They have the best coverage. This is possible because Wasantara net is owned by PT Pos (postal office). They leverage on their postal outlets (offices), which are available in many parts of Indonesia. 

The following table describe statistics of Indonesian internet subscribers and users (source APJII) [4].

Table 1. Indonesian internet subscribers and users

$\begin{array}{cccc}\begin{array}{c}\text { Subscribers \& Users Internet Estimates } \\ \text { Year }\end{array} & \begin{array}{c}\text { Subscribers } \\ \text { Users }\end{array} & \text { Remarks } \\ 1996 & 31.000 & 110.000 & \\ 1997 & 75.000 & 384.000 & \\ 1998 & 134.000 & 512.000 & \\ 1999 & 256.000 & 1.000 .000 & \text { Estimates } \\ 2000 & 384.000 & 1.450 .000 & \text { Estimates } \\ 2001 & 511.000 & 1.980 .000 & \text { Estimates }\end{array}$

It is estimated that the number of Indonesian internet users by year 2004 is targeted to be 5 million. Compared to the number of Indonesian inhabitants, this number is only 2,4 percent. Most of them are in Jakarta city and Java Island. For the near future, we hope the percentage will increase along the development ICT infrastructure. Unfortunately, the economic crisis is sweeping Indonesia caused the development will be very expensive.

\subsection{IndonesiaDLN and the Digital Divide}

Paying close attention to above situations, the development of digital library network in Indonesia will be an appreciable contribution in narrowing the gaps. The IndonesiaDLN at least will work at the following parameters:

- Content; The number of local language contents will increase and many sectors -education, health services, citizen resources, NGOs, SMEs, etc - will put their contents online that will have local relevance and usefulness.

- Community; The digital library systems are not be stand-alone systems, but there are connections between them. Their collections are unified, managed, and presented in an integrated digital library network system. These will promote discussion within the communities and many forums will be established whether using web-based application or extended by email.

- Capacity; Digital library systems especially at the research and education institutions will contain useful information and knowledge they have locally. For example the electronic theses and dissertation, research reports, etc will be very useful to increase nation's information literate and narrow the skill gaps. Digital library network also can be utilized to deliver e-learning and distance learning materials.

- Cooperation; It is a logical impact of the communication in the communities. By publishing local information into digital library network, every institution will have chances to open collaboration with other people or institutions. This can happen at the level of interpersonal, state, national, or regional.

\section{Basic Design of the IndonesiaDLN}

The configuration of IndonesiaDLN should consider the realistic condition of ICT infrastructure in Indonesia. Otherwise, the networking design will not work.

\subsection{The Architecture of Data Integration}

There are two methods of data integration: global defined from local and global independent from local. While the first can be implemented using Database Schema Integration, and the second using Data Warehousing or Data Intermediation [5]. The most relevant method with IndonesiaDLN condition is the second one, where in the future database structure of partners' digital library will be different. 


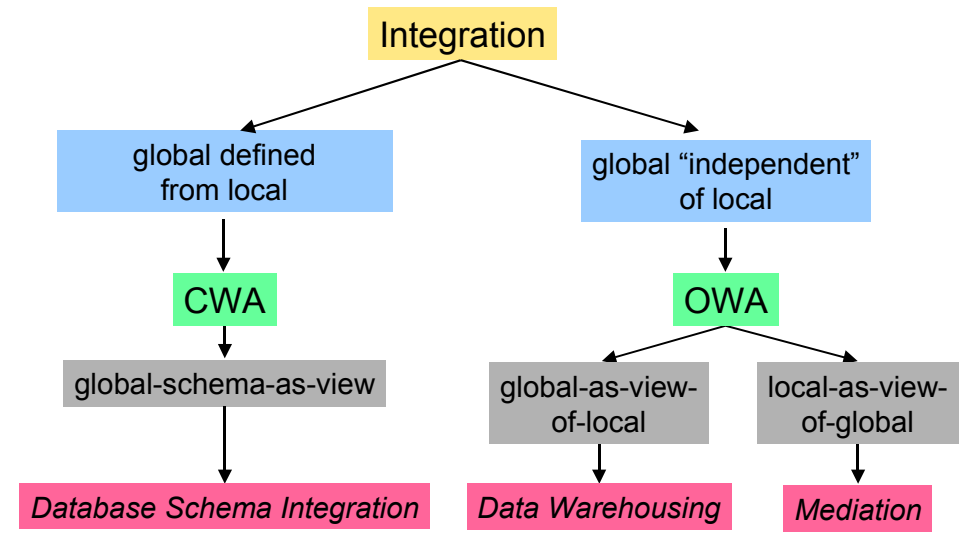

Figure 2. Paradigm of data integration [5]

Data Warehousing will collect all data of interest in a central place and a web site is built on top of it. It is easy to support queries and transaction, but hard to modify because the warehouse is not connected to the providers.

Data Intermediation will reroute queries to the sources. Data remains in web sources so that data are guaranteed to be up-to-date.

\subsection{Data Integration for IndonesiaDLN}

Both architectures (data warehousing and data intermediation) require good internet connection that often difficult to be found at most area of developing countries. For example, students at University of Irian Jaya difficult to find a good internet access to send queries to ITB (Institut Teknologi Bandung) digital library server. This cause data warehousing or data intermediation that is implemented at ITB will not answer their need.

In Indonesia, only few of research and education institutions have dedicated internet connection. Most of them only have a dial-up or even have no connection at all.

But now we can find internet kiosks that are growing around the places. It is a good situation where we can consider it as a positive factor in designing digital library network at developing countries, especially in Indonesia.

\subsection{Mirroring Unified Metadata Architecture}

Considering above conditions, we should design architecture of the digital library network that can answer our need of access to the sources of information. Problems such as internet bandwidth, availability, and access can be solved by bringing the information sources close to the users.

Using this paradigm, users don't have to send their queries to the publishers' servers but to the nearest mirror server. This will make the queries to be processed and the response to be received fast. Figure 3 describes architecture of this paradigm. 


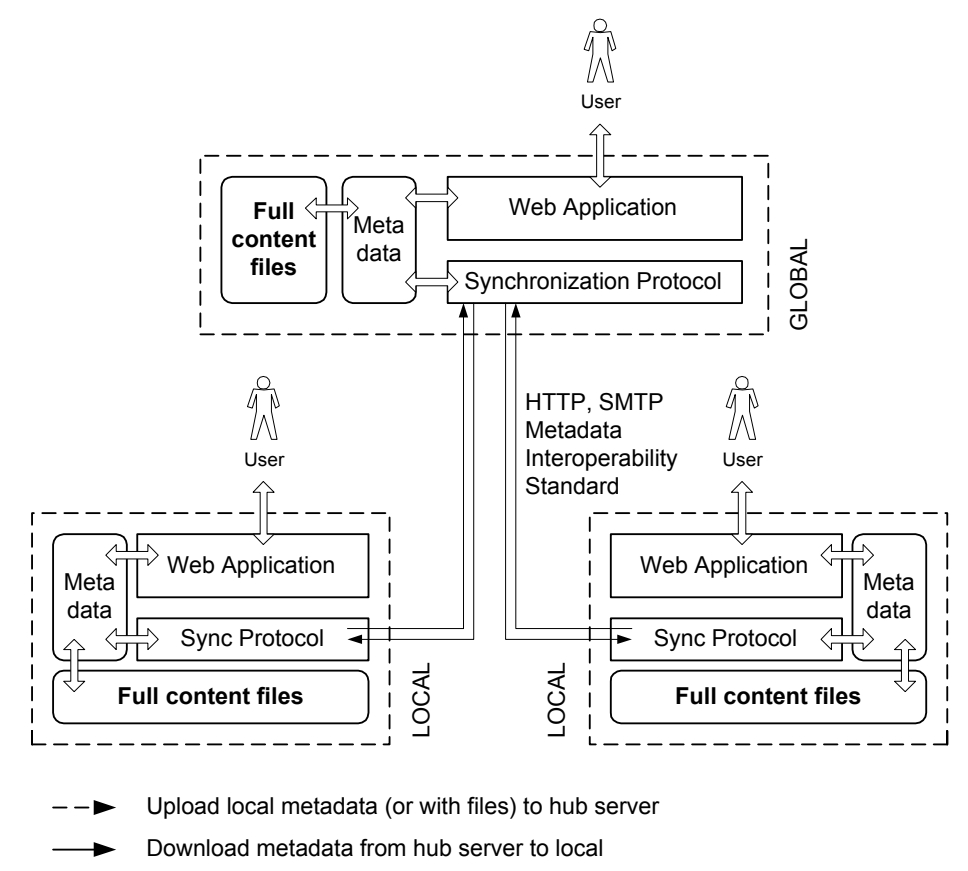

Figure 3. Mirroring unified metadata architecture.

From above figure we can see that there are a Hub Server (global) and many Partner Servers (local). Partner server will manage partner's full content files with their metadata, while the Hub server will manage metadata from all partners and full content files from some partners especially from partner with non-dedicated internet connection.

Regularly, partners will synchronize metadata of their 'public' accessible collections to the Hub, using HTTP or SMTP protocol. Partners also can 'mirror' their full content files to the Hub using HTTP protocol. This mirroring is useful especially for partners that don't have dedicated internet connection. Their collections will remain on the Hub so that users still can download and access their collections even though the local servers are not online.

To serve their users, partners can 'download' selected or whole metadata from the hub using HTTP or SMTP protocol. During the synchronization process, the metadata will automatically extracted and stored into local metadata table. Then, users can search, browse, and read metadata from all partners locally. Users don't have to visit the hub server or to every partner's server in order to find information they need. We mirror the unified metadata at the hub server into our local server.

Because the full content files are still remaining at partners or hub servers, users have to download directly from the source servers. They can use dial-up connection or order via email.

Partners can do the synchronization whether they use dedicated internet connection, dial-up, or even their servers behind a proxy. Of course partner should also mirror their files into hub server if their connections are not dedicated.

\subsection{Synchronization Services}

Synchronization will be done at partner side. Figure 4 describes the services required during the synchronization. 


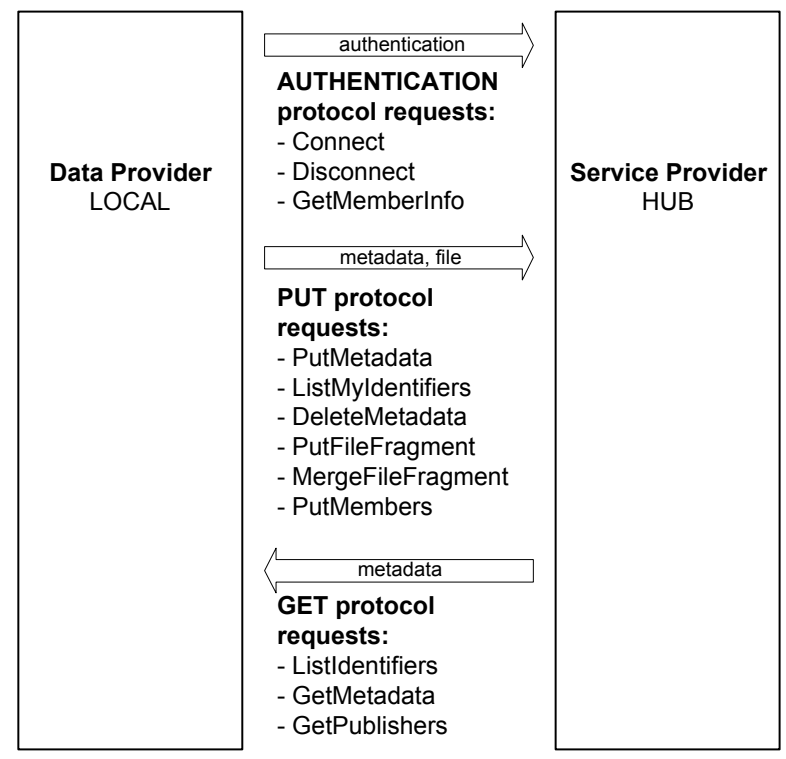

Figure 4. IndonesiaDLN synchronization services

The services are grouped into three functions; AUTHENTICATION, PUT, and GET. Authentication is required by partner's server before synchronize metadata. Every partner has its Publisher_ID and Publisher_SerialNo that are registered and generated by the Hub.

PUT protocol requests are facilities for partner to send its metadata or files to the Hub. Partner also needs to register its members to the Hub. This registration is required in order the members are able to get access to other partners server without have to do registration many times.

GET protocol requests are facilities for partner to get the unified metadata from the Hub. The metadata from all other partners then will be stored into its local database. Partner also can get publishers information from the Hub. This information is needed by users to contact publisher of the displayed metadata.

\subsection{Interoperability Metadata Standard}

Metadata format at local server could be independent from the global. To overcome this metadata format differences, we have declared a metadata standard called "IndonesiaDLN Interoperability Metadata Standard" [7]. This standard was derived from NDLTD (Networked Digital Library of Theses and Dissertation, Virginia Tech) interoperability metadata standard [8].

Both standards are using the Dublin Core Metadata Element Set [6]. Selection of Dublin Core as the adopted standard is a right choice because it will open further international collaboration on digital library network. All digital library servers at IndonesiaDLN should use this standard for the synchronization. The synchronization protocol at local server will do the metadata conversion from local metadata format to the standard metadata interoperability format, and vice versa.

\subsection{XML-based Transaction}

Metadata, publisher, and member data are formatted in XML during transaction between partner and hub. This method will open wider collaboration with other digital library and distance learning efforts to build one big national digital library network. For example, publisher record for the HUB is formatted like figure 5.

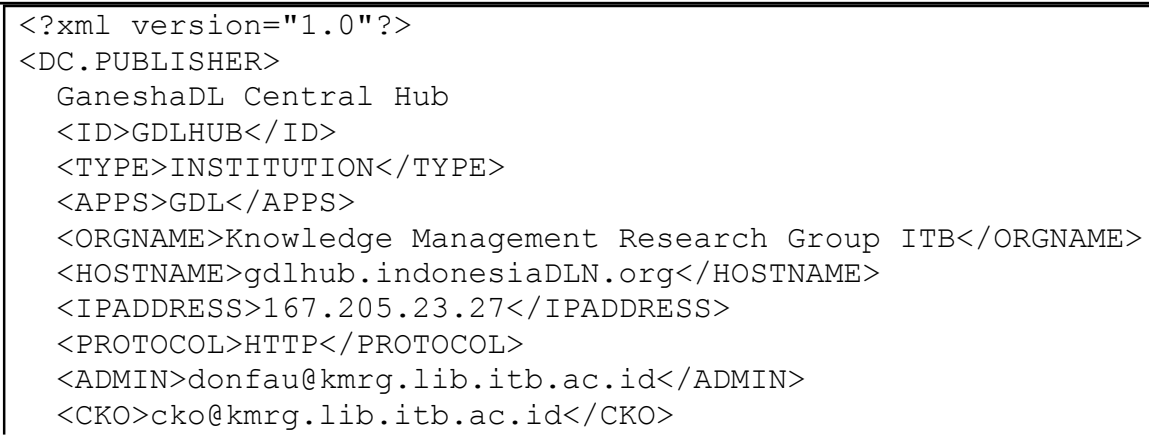


Figure 5. Example of XML format for Publisher data

\section{The Mother Network of The Digital Library Networks}

There are other efforts such as the Digital Heritage Network, SME/ Agriculture Network, Human Right Information Network, Bibliographic Network, and Distance Learning Network. All of these networks can be integrated under IndonesiaDLN easily as long as they use IndonesiaDLN Interoperability Metadata Standard for exchange.

\subsection{Architecture of the IndonesiaDLN}

Figure 6 bellow describes how the above stated networks will be integrated under IndonesiaDLN.

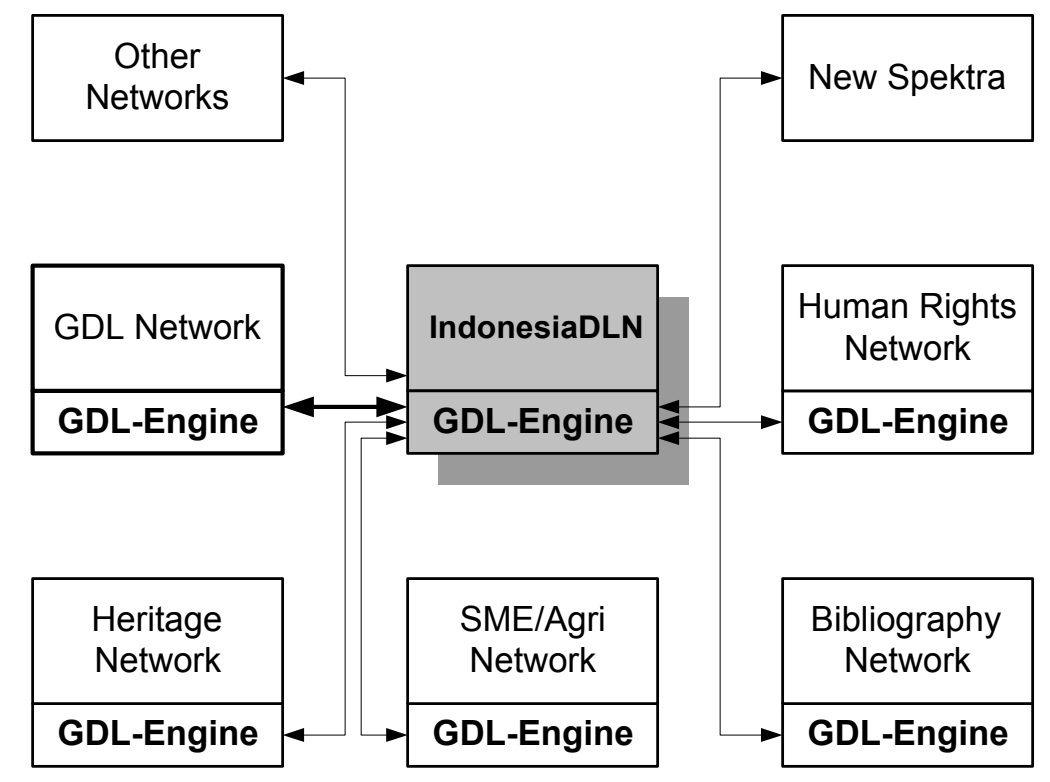

Figure 6. Architecture of IndonesiaDLN as Mother network of digital library networks

From figure 6 above we can see many networks can be integrated into one big network. For this purpose, GDL Ganesha Digital Library- will be developed to become the main engine of the Network. GDL is now being developed modularly so that it can be used for different environments and purposes.

The most important part of the software is the GDL-Engine that will provide facilities and services to develop a web-based digital library. The services would be: membership, personal directory, authentication, search engine, content browsing, and the exchange protocol. The most important service is the exchange protocol.

\subsection{The Working Network}

IndonesiaDLN was launched last June 2001. The first network under IndonesiaDLN is GDL-Network. It is assorted of the digital library servers that use GDL as their server application software.

For this moment, there is only one hub server, namely GDL-Hub that acts as the mediator among the digital library servers. There are 13 digital library servers under GDL-Network, and more than 15 institutions are in progress of developing their digital library server using GDL. Most of the servers are running on Microsoft Windows 98/2000 and another are on Linux and FreeBSD. They connect to GDL-Hub using dial-up and dedicated internet connection.

GDL also can be installed behind proxy. The collections still can be synchronized with the GDL-Hub and the server also can download the metadata from the Hub. This feature enable installation of GDL at internet kiosks to wider the distribution of information.

\subsection{Works in Progress}


We are now in progress of developing digital library system for heritage, human rights (NGO), and SME -the Small and Medium scale Enterprises. We are also planning for the development of digital library network for distance learning. All of these networks are based on GDL-Engine.

Human Rights Digital Library Network is developed by KMRG ITB in cooperation with EIUDP -the CIDA project for the eastern Indonesian universities, Simon Fraser University Canada, YLBHI -the Indonesian Foundation for Human Rights, and CNRG ITB. While SME Digital Library Network is developed by KMRG ITB in cooperation with YLTI and PPAU-Ilmu Hayati ITB.

Each of the networks will have a Hub server and then will be integrated into IndonesiaDLN Hub server. Using any digital library application, users can access any type of information provided by the IndonesiaDLN. User with Heritage Digital Library application can download and read information delivered by other users that use SME Digital Library application, and vice versa. This interoperability is possible along using the IndonesiaDLN Metadata Standard.

\section{Latest Status of IndonesiaDLN}

The growth of IndonesiaDLN is counted to be very fast. Only in two months after its lunching, the number of registered partners is reached 43. From this number, 14 of them have successfully connected to GDL-Hub and shared their electronic collections. The number is keep increasing by now.

\subsection{Partner and Identifier}

A Partner is a personal or an institution that installs a digital library server and joins IndonesiaDLN to share the electronic collections. Everybody can download and install GDL software, but to become a partner of IndonesiaDLN, s/he has to register first.

Every partner has Publisher_ID that is obtained after registering its server to IndonesiaDLN/GDL-Network administration. Publisher ID is very important because it becomes identity of the server and part of identity for every record disseminated to the network. Publisher_ID consist of Area Code, Type of Library, and Name of Institution or Individual. For example JBPTITBPP consists of:

$\mathrm{JB}=$ Jawa Barat (West Java, Area)

$\mathrm{PT}=$ Perguruan Tinggi (Higher Education, University, or Institute)

ITB = Institut Teknologi Bandung (Name of the Institution)

PP $=$ Perpustakaan Pusat (Central Library, sub-name of the Institution)

Metadata or record identifier will be started with this Publisher_ID. It will be easier to trace from which partner is an information comes from.

\subsection{Status of Current Partners}

For this moment, partners of IndonesiaDLN are also partner of GDL-Network. Currently there are 14 institutions and 1 personal joined as partner and have been successfully connected to the GDL-Hub. The following table describes their publisher code, name, and number of contributions (records) by July 31, 2001, sorted alphabetically. The online version can be accessed from http://gdlhub.IndonesiaDLN.org/.

Table 2. The successfully connected partners of IndonesiaDLN

\begin{tabular}{|l|l|l|r|r|}
\hline No & Publisher_ID & Name & Connection & Recs \\
\hline 1 & ACPTUNSYIAH & Universitas Syah Kuala & Dedicated & 49 \\
\hline 2 & IJPTUNCEN & Universitas Cendrawasih & Dial-up & 26 \\
\hline 3 & JBPTIPBMMA & Magister Manajemen Agribisnis - IPB & Dedicated & 24 \\
\hline 4 & JBPTITBPP & ITB Central Library & Dedicated & 720 \\
\hline 5 & JIPTUMM & Universitas Muhammadiyah Malang & Dedicated & 95 \\
\hline 6 & JKPKBPPK & Badan Litbang Kesehatan & Dedicated & 58 \\
\hline 7 & JKPKELNUSA & PT ELNUSA Tbk & Dedicated & 78 \\
\hline 8 & JKPKFORLINK & Dana Mitra Lingkungan & Dial-up & 21 \\
\hline 9 & JKPNPNRI & Perpustakaan Nasional Republik Indonesia & Dial-up & 1 \\
\hline & & & &
\end{tabular}




\begin{tabular}{|l|l|l|r|r|}
10 & JKPTBINUS & Bina Nusantara University & Dedicated & 16 \\
\hline 11 & JKUNUAJ & Atma Jaya Catholic University & Dedicated & 3 \\
\hline 12 & SAPTUNSRAT & Universitas Sam Ratulangi & Dedicated & 236 \\
\hline 13 & SGPTUNHALU & Universitas Haluoleo & Dial-up & 4 \\
\hline 14 & YOPTIAIN & IAIN Sunan Kalijaga & Dial-up & 1 \\
\hline 15 & JBPEISMAIL & Personal: Ismail Fahmi & Dial-up & 54 \\
\hline
\end{tabular}

The location of Universitas Syah Kuala (ACPTUNSYIAH) is at western of Indonesia, while Universitas Cendrawasih (IJPTUNCEN) is at eastern of Indonesian, as shown by figure 7. They are separated by thousands of islands each other. Universitas Sam Ratulangi and Universitas Haluoleo are located out side of Java, while other institutions are in Java. Dana Mitra Lingkungan (JKPKFORLINK) is a sample of partner that installs its GDL server behind proxy.

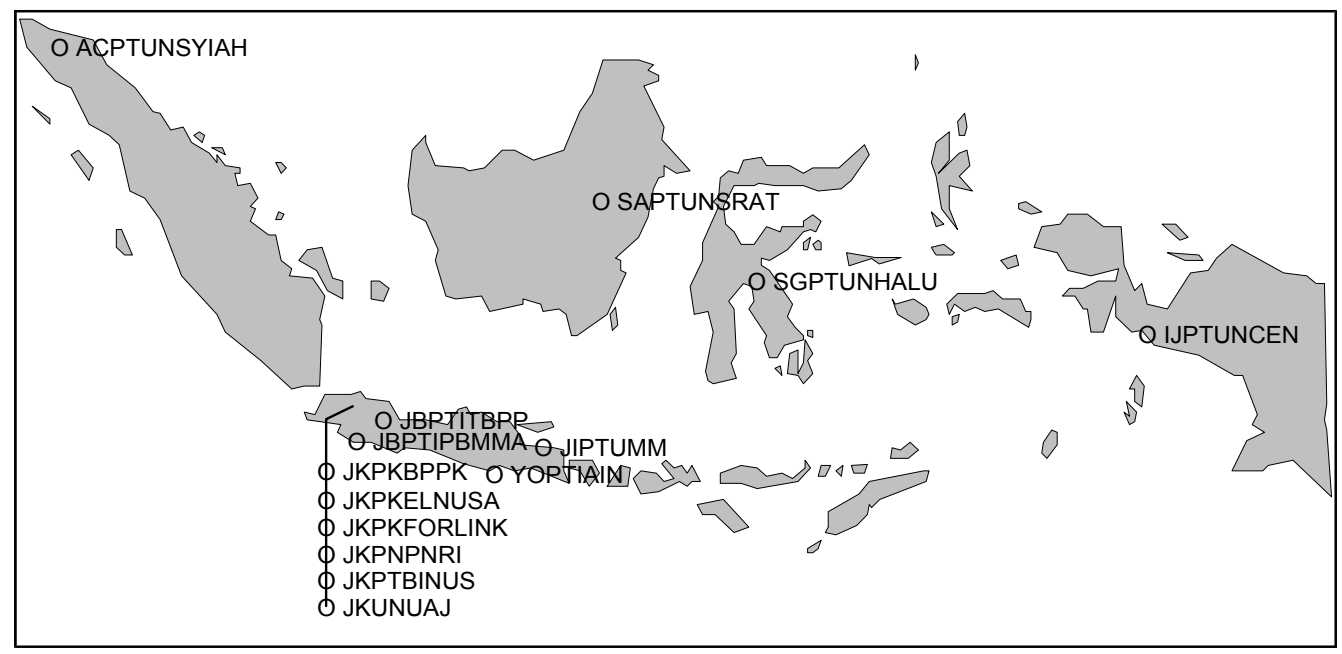

Figure 7. The Distribution Map of IndonesiaDLN Partners

At the end of the table, we can see a sample of Personal application of GDL. Author (JBPEISMAIL/Ismail Fahmi) makes experiment with the installation of GDL on his notebook; uploading his papers, articles, and other resources into his local server. Periodically using dial-up connection, he synchronizes the collections with the GDL-Hub in order to his electronic collections can be disseminated and accessed widely.

From above table we can conclude that the connection -dial-up or dedicated- is not the barrier in sharing and accessing the electronic collections. Every partner can download all others collections into its local server for further accesses of its community.

In our publisher database, actually there are 43 registered publishers. They are in progress of developing digital library servers before can share their electronic collection with IndonesiaDLN.

Number of partners is keep growing. It is indicated by many institutions that have expressed their interest to develop digital library and join IndonesiaDLN. For example 12 IAINs -the Islamic Religion Institute- will develop their servers with the help of KMRG. Other institutions that will develop their servers in the near future are R\&D of Health Department of Indonesia (5 branches will be integrated), University of YARSI, and STIE Perbanas. 


\subsection{Profile of the Electronic Collections}

IndonesiaDLN manages many types of resources. The following table describes the types that currently shared in the network. It appears that gray literature, research reports, theses, and proceeding are the most published resources.

Table 3. Type of IndonesiaDLN electronic resources

\begin{tabular}{|c|l|r|r|}
\hline No & \multicolumn{1}{|c|}{ Type } & Total & \multicolumn{1}{c|}{$\%$} \\
\hline 1 & Gray Literature & 282 & 20.36 \\
\hline 2 & Research Report & 241 & 17.40 \\
\hline 3 & Theses & 206 & 14.87 \\
\hline 4 & Proceeding & 165 & 11.91 \\
\hline 5 & Multimedia & 135 & 9.75 \\
\hline 6 & Journal & 129 & 9.31 \\
\hline 7 & Undergraduate Works & 80 & 5.78 \\
\hline 8 & Distance Learning & 48 & 3.47 \\
\hline 9 & Publication & 30 & 2.17 \\
\hline 10 & Internet Directory & 25 & 1.81 \\
\hline 11 & Software & 15 & 1.08 \\
\hline 12 & Course Material & 11 & 0.79 \\
\hline 13 & Clipping & 8 & 0.58 \\
\hline 14 & E book & 4 & 0.29 \\
\hline 15 & Expertise Directory & 3 & 0.22 \\
\hline 16 & Dissertation & 3 & 0.22 \\
\hline
\end{tabular}

There is an interesting fact. We found that the undergraduate works only stand at seventh rank. Compared with table 6 , number of undergraduate students stands at the first rank. It is caused by an opinion that undergraduate works are not worth enough to be published in the digital library or shared publicly.

Probably we should change the opinion regarding to the fact that most of the digital library users are from undergraduate students. It is often that we found many undergraduate works have good quality and are valuable.

\subsection{Profile of IndonesiaDLN Members}

A Member is an individual that has registered to a digital library server. User has to register in order to get full access to the digital library server. As a guest, user can't download the full texts.

GDL supports roaming membership. It means user can register at any digital library servers and use the same account to login to any GDL servers that are connected to GDL-Hub.

Table 4 describes number of members from each Partner. JBPTITBPP -number one in the rank- is the oldest digital library server published by ITB Central Library. From this table we can see some Partners such as JIIYPIA and JBPTITBPSUD are in the list. They have successfully installed GDL servers and connected to the GDL-Hub, but they haven't shared any information.

Table 4. The distribution of members by Partners

\begin{tabular}{|c|l|r|r|l|r|}
\hline No & Publisher_ID & Members & No & Publisher_ID & Members \\
\hline 1 & JBPTITBPP & 2610 & 10 & JKPKELNUSA & 12 \\
\hline 2 & GDLHUB & 140 & 11 & IJPTUNCEN & 7 \\
\hline 3 & JKPTBINUS & 53 & 12 & JIIYPIA & 6 \\
\hline 4 & ACPTUNSYIAH & 51 & 13 & JKUNUAJ & 6 \\
\hline 5 & JIPTUMM & 51 & 14 & DEFAULT & 4 \\
\hline 6 & JBPTIPBMMA & 39 & 15 & JIUNUMM & 2 \\
\hline 7 & SAPTUNSRAT & 36 & 16 & JKDMLFORLINK & 2 \\
\hline 8 & JKPKBPPK & 28 & 17 & ACPETOPGAN & 1 \\
\hline 9 & SGPTUNHALU & 20 & 18 & JBPTITBPSUD & 1 \\
\hline
\end{tabular}


Table 5 shows countries from where the members are coming from. Most of the members are from Indonesia. But it is interesting that 113 members $(3,7 \%)$ are coming from out side of Indonesia.

Table 5. Members according to their countries

\begin{tabular}{|r|l|r|l|l|r|}
\hline No & Tountry & Total & No & Country & Total \\
\hline 1 & Indonesia & 2949 & 18 & Spain & 2 \\
\hline 2 & Malaysia & 15 & 19 & Andorra & 1 \\
\hline 3 & United States & 14 & 20 & Bangladesh & 1 \\
\hline 4 & Japan & 10 & 21 & Brazil & 1 \\
\hline 5 & Canada & 9 & 22 & Bulgaria & 1 \\
\hline 6 & Australia & 7 & 23 & Chile & 1 \\
\hline 7 & United Kingdom & 7 & 24 & Hongkong, PRC & 1 \\
\hline 8 & Germany & 5 & 25 & Iran & 1 \\
\hline 9 & Netherlands & 4 & 26 & Jerman & 1 \\
\hline 10 & Singapore & 4 & 27 & Lebanon & 1 \\
\hline 11 & Vietnam & 4 & 28 & Morocco & 1 \\
\hline 12 & Brunei Darussalam & 3 & 29 & Pakistan & 1 \\
\hline 13 & Egypt & 3 & 30 & Qatar & 1 \\
\hline 14 & India & 3 & 31 & Romania & 1 \\
\hline 15 & Saudi Arabia & 3 & 32 & Sweden & 1 \\
\hline 16 & Belgium & 2 & 33 & Thailand & 1 \\
\hline 17 & Czech Republic & 2 & 34 & United Arab Emirates & 1 \\
\hline
\end{tabular}

Table 6 describes the job type of members. Most of the members are undergraduate students and other positions that are mostly at research and education institutions. It is interesting that members from private company stand at second rank. It shows that they need to find research information from university and it will open future cooperation between universities community with the private sectors.

Table 6. Members according to their jobs

\begin{tabular}{|c|l|r|r|}
\hline No & \multicolumn{1}{|c|}{ Member Status } & Total & \multicolumn{1}{c|}{$\%$} \\
\hline 1 & S1 & 1276 & 41.58 \\
\hline 2 & Empl Private Company & 274 & 8.93 \\
\hline 3 & Diploma & 241 & 7.85 \\
\hline 4 & Others & 241 & 7.85 \\
\hline 5 & S2 & 195 & 6.35 \\
\hline 6 & Librarian & 152 & 4.95 \\
\hline 7 & Lecturer & 145 & 4.72 \\
\hline 8 & Researcher & 127 & 4.14 \\
\hline 9 & Public & 103 & 3.36 \\
\hline 10 & Empl Public Sector & 89 & 2.90 \\
\hline 11 & Empl Univ & 76 & 2.48 \\
\hline 12 & Student & 47 & 1.53 \\
\hline 13 & Teacher & 41 & 1.34 \\
\hline 14 & S3 & 34 & 1.11 \\
\hline 15 & Empl NGO & 28 & 0.91 \\
\hline
\end{tabular}

\section{Conclusion}

Now, we come to the conclusions. IndonesiaDLN is a new hope especially for Indonesian people to narrow the digital gaps between them. It is proven that institution anywhere in Indonesia as long as has internet connection, can implement the GDL system and join IndonesiaDLN. They can share and download electronic collections in the network.

The use of Dublin Core Metadata Element Sets will open wider collaboration in the future. Many digital library 
networks can be integrated within IndonesiaDLN. Furthermore IndonesiaDLN is ready for wider international collaboration in developing digital library network especially among developing countries.

\section{References}

[1] FAHMI, ISMAIL, Mirroring Unified Metadata as the Solution for the Digital Library Network in Indonesia, 2001.

[2] RAO, MADAMMOHAN, Struggling with the Digital Divide, OTI, 2000. http://www.isoc.org/oti/articles/1000/rao.html.

[3] RAHARDJO, BUDI, Indonesian Internet Statistics, 2001, http://www.insan.co.id/.

[4] APJII, Indonesian Internet Statistics, 2000, http://www.apjii.or.id.

[5] IBRAHIM, Ismail Khalil, Data Integration in Digital Libraries: Approaches and Challenges, 2001.

[6] DC, Dublin Core Metadata Element Set, Version 1.1, 1999, http://purl.org/dc/documents/rec-dces-19990702.htm.

[7] FAHMI, Ismail, Team, Standard Interoperabilitas Metadata Untuk Pertukaran Metadata Koleksi Elektronik di Lingkungan IDLN, 2000, http://idln.itb.ac.id/meeting/Oktober2000/interoparability_metadata_standar_idln.htm.

[8] FOX, Edward, Interoperability Metadata Standard for Electronic Theses and Dissertations -- version .02, 2000, http://www.ndltd.org/standards/metadata/current.html.

*) Ismail Fahmi, Ir. Graduated from undergraduate program of Electrical Engineering Department of ITB on 1997. His interests are on network management, knowledge management, and digital library. He is a researcher at Computer Network Research Group ITB (CNRG), the Asian Internet Interconnection Initiatives ITB (AI3), the head and founder of Knowledge Management Research Group ITB (KMRG), general secretary of IndonesiaDLN, and head of Knowledge Resource Development Foundation. He is the designer and creator of GDL version 1 until 3.1, and with his team is now preparing for GDL 4.0, SME/Agri Network, Human Right Networking, and Digital Heritage Network. He can be reached at ismail@itb.ac.id, or http://netmon.itb.ac.id/ ismail/.

\footnotetext{
[1] Paper for International Paper Contest ASIST Annual Conference, Washington, DC, November 3-8, 2001 [2] Knowledge Management Research Group, Institut Teknologi Bandung

IndonesiaDLN - Verbatim copying of this article is permitted.
} 